\section{Bain Circuit Confusion?}

\section{DeAr SiR:}

I appreciate the letter by Drs. Keenan and Boyan; I believe we are thinking along very similar lines. It is important to consider the points made in their letter to approach the existing confusion regarding the Bain circuit on the issues of rebreathing and carbon dioxide elimination.

We agree that the ratio $\dot{V}_{E} / \dot{V}_{F}$ controls rebreathing. The degree of rebreathing, defined as the total volume of gas entering the airway and lung in relation to the volume of fresh gas entering the breathing circuit, increases the more $\dot{V} E$ exceeds $\dot{V}_{F}$ and is low when $\dot{V}_{E}$ is smaller than $\dot{V}_{F}$. Rebreathed alveolar gas and fresh gas come together in the airway (and in the Bain circuit) entering the alveoli as a mixture; one can separate them mathematically into a volume of re-inhaled gas (which is in equilibrium with the $\mathrm{Pa}_{\mathrm{CO}_{2}}$ of blood and cannot accept further carbon dioxide) and a volume of fresh gas $\left(\dot{V}_{F}\right)$ which is free of carbon dioxide and only it can therefore take part in the alveolar gas exchange.

Theoretical studies of the Bain circuit have always concentrated on the volume and degree of rebreathing and anaesthetists have been cautioned not to allow rebreathing, since it was thought to impair carbon dioxide elimination. On the other hand, the $\mathrm{Pa}_{\mathrm{CO}_{2}}$ remained normal with a fresh gas flow near the patient's volume of alveolar ventilation as long as $\dot{V}_{E}$ was greater than $\dot{V}_{F}$, i.e., as long as there was rebreathing. This finding is in contradiction to the often stated principle, that rebreathing must be avoided with Ayre's $T$ piece.

We also agree that in the absence of $\dot{V}_{F}$ there would be total rebreathing and no alveolar ventilation; however, this is true regardless of the magnitude of $\mathrm{VE}$; there is also no carbon dioxide elimination. The removal of carbon dioxide depends then entirely on VF or, more specifically, on the fraction of $\dot{V}_{F}\left(f \times \dot{V}_{F}\right.$, as stated by Conway') which enters the alveoli and takes part in gas exchange.

VF enters the breathing circuit, but an equal volume of gas leaves the circuit; with the exception of a short time during induction of anaesthesia, the only source of vented gas is fresh gas and the only source of carbon dioxide is the patient's carbon dioxide production. Since the alveolar ventilation, as defined in Keenan and Boyan's letter, can never be greater than $\dot{V}_{F}$ but will always be smaller due to the deadspace, and since the volume of gas vented from the circuit must be equal to $\dot{V}_{F}$, it can be deduced that the volume of gas leaving the circuit will always be greater than the volume of alveolar ventilation (f $x \dot{V} f)$. Hence, the breathing system can not be a cause of carbon dioxide retention; all carbon dioxide entering the breathing tube of the Bain circuit must leave the circuit regardless of $\mathrm{VE}$ or the degree of rebreathing.

"A satisfactory mathematical description would be proof that the function of the Mapleson D system is truly understood." A mathematical description requires the exact definition of function of each factor. The assumption that the distribution of carbon dioxide within the circuit (as determined by the degree of mixing or rebreathing) should alter $\mathrm{Pa}_{\mathrm{CO}_{2}}$ or elimination of carbon dioxide has not been proven; a change in inspired carbon dioxide, as an indicator of rebreathing, did not cause corresponding changes in either $\mathrm{Pa}_{\mathrm{CO}_{2}}$ or elimination of carbon dioxide, as I showed in my paper. If this is correct, then a formula designed to predict the $\mathrm{Pa}_{\mathrm{CO}_{2}}$ with the Bain circuit may not need an indicator for rebreathing.

Do our points of view agree? Is all the confusion then due to a faulty interpretation of rebreathing? We should work together to solve this problem and take the complexity out of an essentially very simple breathing system.

W.E. Spoerel, M.D., F.R.C.P.(C), Professor and Chairman, Department of Anaesthesia, University of Western Ontario, London, Ontario.

\section{REFERENCE}

1. Seeley, H.F., Barnes, P.K. \& Conway, C.M. Controlled ventilation with the Mapleson D system: A theoretical and experimental study. Brit. J. Anaesth. 49: 107 (1977).

\section{Bain Circuit}

DEAR SIR:

Re: Rebreathing \& Carbon Dioxide Elimination with the Bain Circuit. W.E. Spoerel. Canad. Anaesth. Soc., Jour. 27: 237 (July 1980).

Whilst I agree with the main conclusion of Professor Spoerel concerning the carbon dioxide retention resulting primarily from an inadequate $\dot{V}_{F}$, I believe the information he has given concerning the utilization of $\dot{V}_{F}$ to be misleading.

The paper quoted by Rose \& Froese ${ }^{1}$ was concerned with paediatric anaesthesia. 


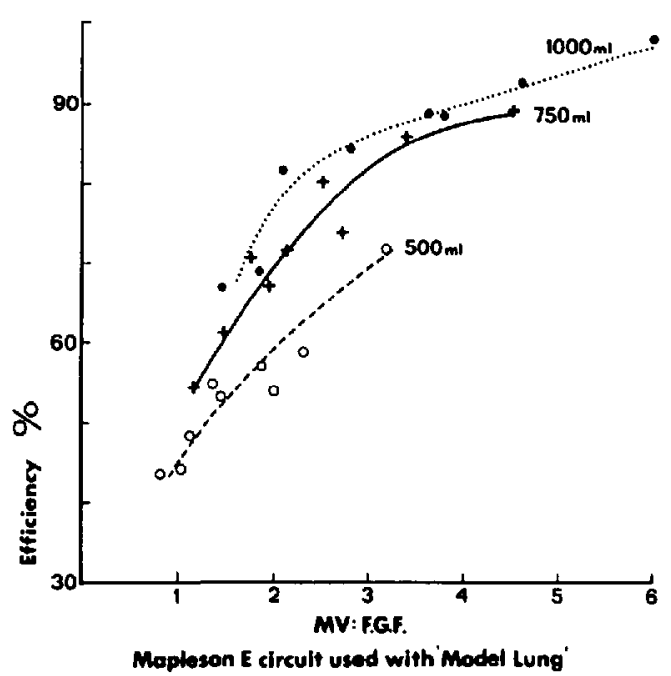

We have found the utilization of $V_{F}$ in the adult with rebreathing circuits to be less efficient than those reported above. ${ }^{2.3}$ Tidal volume and MV appeared to have a significant effect even up to ratios of $\dot{V}_{E}: \dot{V}_{F}$ of 3:1. Increasing $\dot{V}_{E}: \dot{V}_{F}$ above 1.5:1 will therefore influence the $\mathrm{FACO}_{2}$.

Enclosed is a copy of a diagram relevant to Mapleson E circuit (functionally the same as the Bain).

\section{S.L. Snowdon,} Senior Lecturer,

University Dept. of Anaesthesia, The University of Liverpool.

\section{REFERENCES}

1. Rose, D.K. \& Froese, A.B. 'The regulation of $\mathrm{Pa}_{\mathrm{CO}_{2}}$ during controlled ventilation of children with a T piece.' Canad. Anaes. Soc. J. 26: 104 (1979).

2. Snowdon, S.L., Powell, D.L., Fadl, E.T., \& UTrING, J.E. 'The circle system without absorber.' Anaesthesia 30: 323-332 (1975).

3. SNOwdon, S.L. 'An Adaptation of the Mapleson E Circuit for Controlled Ventilation.' $\mathrm{Br}$. Jour. Anaes. 49: 572 (1977). 